\title{
SUPERVISION AS A KIND OF QUALITATIVE EVALUATION
}

\author{
Maria Grazia Riva
}

University of Milan-Bicocca, Italy

Nikoleta Ratsika

Technological Educational Institute (TEI) of Crete, Greece

\begin{abstract}
The contribution presents a reflection on supervision as one of the possible forms of qualitative evaluation, in the field of work with adult educators. Supervision structures a context where theory and practice, emotions and cognitions, values, representations and fears, anxieties and conflicts can be made to dialogue in continuation. The supervisor continuously offers feedback and interpretations to the educators, thanks to attentive listening and decodes what they express. The constructivist approach to Evaluation, on the one hand, gives full value to the subjectivity of the actors involved in the evaluation process and aims to interpret and understand. So, we can call it hermeneutic evaluation (Perla, 2004). Hermeneutic evaluation sets the problem of finding the meaning of the points of view of the participants. This is where the meeting point with the supervision activity, which consists precisely of a practice guided by a leader who helps the educators to better understand their theoretical frameworks of reference and their basic educational models, lies. Supervision and Evaluation therefore represent two important tools for developing the professionalism of the operators, as shown by the case-study analyzed. The practice of supervision is part of a path of lifelong learning and education (Oggionni, 2013; Zannini, 2005), which passes through experimentation, evaluation and redesigning, in the face of constant monitoring of the needs and learning of the individual and of the team.
\end{abstract}

Keywords: Supervision, Evaluation, Education, Training, Quality.

\section{Introduction}

The contribution presents a reflection on one of the possible forms of qualitative evaluation, in the field of work with adult educators. This analysis has been triggered by the research activity and exchange of reflections between researchers and practitioners - on the educational practices concretely performed in everyday work in the field -, in the European EduEval Evaluation for Adult Evaluation Staff - project ${ }^{5}$. From the research carried out in the first year of life of the project in the different countries involved, the presence emerged of multiple models and types of evaluation of educational work, both quantitative and qualitative. On the one hand, the desk research highlighted indicators and guidelines, prepared by various European and national bodies, aimed at orienting the evaluation activities towards the best

\footnotetext{
${ }^{5}$ Evaluation for the Professional Development of Adult Education Staff. Project Number: 538743-LLP-1-2013IT-GRUNDTVIG-GMP. Grant Agreement Number: 2013-3800/001/003. This project has been funded with support from the European Commission.This document reflects the views only of the authors, and the Commission cannot be held responsible for any use which may be made of the information contained therein. http://www.edueval.eu/
}

http://dx.doi.org/10.17770/sie2015vol4.493

(C) Rēzeknes Augstskola, 2015 
practices whereas; on the other hand, the interviews both with the management staff of providers of socio-educational services - with official and unofficial evaluators - have highlighted what happens at the level of concrete daily practices. During the activities, a great challenge, ambivalence and lack of linearity in the behaviour of the various players at stake is always encountered. They project different representations of educational work, of variegated guiding values in their actions with users, as well as of different interpretations of the dynamics present in the events they have to cope with. From the research carried out, we have been able to note a considerable gap between the major European studies, which define guidelines on evaluation in general terms, and the complexity of the problems encountered by evaluators and educators in their evaluation activity in the field ${ }^{6}$.

For this reason, the part of the project devoted to the exchange of practices - concretized both in the workshop in $\mathrm{Crete}^{7}$ in July 2014, which brought together researchers and practitioners from all the partner countries, and in the subsequent phase of writing, using the wiki system ${ }^{8}$ on an online platform - has been very useful to allow all those involved to acknowledge the need for dialogue between the indispensable guidelines and the lists of indicators - necessary for orientation at macro-level - and the claims, the doubts and the problems, brought by the representatives of the educational professions. During these fertile moments of exchange of experiences and practices, some partners brought attention to the role played by supervision as one of the possible forms of evaluation. The reflections that follow intend to resume and develop this part of the results, reached during the first year of life of the EduEval Project.

\section{Supervision of the educational work}

In its strictest meaning, supervision (Oggionni, 2013; Belardi, Wallnofer, 2007) can be dated back to the end of the $19^{\text {th }}$ century in England, when the first forms of social work began to develop. These arose to meet the great increase in poverty and social deterioration, following the chaotic processes of industrialization and the consequent influx to the cities of huge masses of people in search of work. For example, the Barnetts, pastors who worked in Whitechapel, London, began to criticize the policies of assistance offered to the poor, promoting the development of self-help activities on the one hand and, on the other hand, offering socio-educational support to the operators. They suggested weekly interviews, in order to facilitate processes of reflection and reelaboration on the practices, useful for identifying new strategies of action. Other similar activities, anticipating modern supervision, were also developed in

\footnotetext{
${ }^{6} \mathrm{http}: / /$ www.edueval.eu/download/pdf/2.2_Public_Research_Report.pdf

${ }^{7} \mathrm{http}: / / \mathrm{www}$. edueval.eu/recent-events/

${ }^{8} \mathrm{http}: / /$ wiki.edueval.eu/index.php/Main_Page
} 
the United States. In 1871, the Charity Organization Society was founded in New York City, where Mary Richmond, the founder of "social casework" (Richmond, 1917) operated. Ms. Richmond emphasized the importance of the activities of surveying and investigation, necessary to better understand the nature of the users' needs. Volunteers collected information to give to the social workers, in order to have preliminary orientative diagnoses and analyses of the socio-economic processes in course. Expert social workers, called supervisors, used a method of dialogue and consultation to offer help and support to the younger social workers. The model of teaching-learning was based on the master-apprentice relationship, from the medieval and then Renaissance tradition. In this model, considered as equivalent to the father-son relationship, there was the presence of an older and more expert professional, who was accompanied by a younger worker. The latter also interviewed some clients under the supervision of the older worker. This is, moreover, a model of training which is still very present in education, including at university level, for care professions. Supervision plays a leading role in university training for the professional figures (Zannini, 2005; Palmieri, Pozzoli, Rossetti, Tognetti, 2009) of educators, social workers, psychologists, tutors, teachers and nurses, precisely because it tries to connect the theoretical dimension with the practical dimension. The supervisors are figures of experts with a university training but also with great experience in the field.

In Europe, the debate on casework and on supervision developed after World War II, strongly influenced by psychoanalysis (Frabboni, Wallnofer, Belardi, Wiater, 2007; Aichorn, 1978; Bernfeld, 1971; Balint, 1964; Horder, 2001), which had studied the transference between operators and users, for the purpose of freeing the professional field from excessive emotional interference. An intense debate grew up, especially in countries where the welfare state was already structured, like Great Britain, the Netherlands, Scandinavia, Germany, Austria and Switzerland. In particular, in Germany, from the 1950s onwards, there developed a movement of attention to supervision enlightened by psychoanalytical principles, aimed at activating processes of reinterpreting professional practices, listening to the emotional dynamics of transference and counter-transference between operators and users (Dozza, in Contini, 2000). It is, therefore, very easy to understand the historical-social roots of the activity of supervision, connected with important socio-economic movements - such as the full development of the industrial revolution with the consequences on the condition of the population -, as well as its use as a tool of training for young people aspiring to work in the social and educational fields. The practice of interviewing clients, to collect information and better orient the socioeducational action, therefore started to be established from the very beginning. In this way, the centrality of the work on the individual case, of the interpretation of the concrete situations for diagnostic purposes, of listening to the relational dynamics that involved operators and users, "in the way that today 
we know by the name of hermeneutic method or case study" (Belardi, Wallnofer, 2007; Oggionni, 2013; Castellucci, Saiani, Sarchielli, Marletta, 2007), was understood immediately. Supervision gradually became professionalized, thanks also to numerous occasions of national and international discussion and the ever-increasing use of supervision in different fields, in work with individuals, with couples, with groups, with monoprofessional and multi-professional teams (Cellentani, 2004). This allowed a reciprocal contamination between psychological and sociological approaches, reaching the present-day situation in which "multidisciplinary, integrative or meta-theoretical approaches dominate, as a single point of view is not sufficient for the numerous tasks of supervision" (Belardi, in Frabboni, Wallnofer, Belardi, Wiater, 2007).

\section{Evaluation}

There are different approaches to the study of evaluation, such as the positivist-experimental, the pragmatist and the constructivist (Perla, 2004; Hadji, 1995; Scriven, 1991; Palumbo, 2001). The positivist-experimental approach considers evaluation as analysis and verification of objectives, which have been defined a priori. According to this approach, the coherence, pertinence and neutrality of the evaluator are important. The validity and the reliability are based on methodological rigour. Particular emphasis is placed on measurement, that is the quantitative dimension. This approach has been criticized because of its methodological rigidity, that has not always succeeded in adapting variables of the complexity of the education processes. The pragmatist approach, on the other hand, draws attention to the dimension of comparison and of the definition of standards and criteria. In this approach, particular importance is placed on the judgement (and therefore to the "voice" of the different players involved in the evaluation process). These models can be said to be self-referential and linked to indicators, decided only within the system where the evaluation takes place (Perla, 2004). The constructivist approach, on the other hand, gives full value to the subjectivity of the participants involved in the evaluation process, aiming to interpret and understand. Such an approach can also be called hermeneutic evaluation (Perla, 2004), because paying attention to the meanings is given more consideration than measuring the phenomena and the actions, which are the object of the evaluation. Here, attention is paid to the qualitative dimension of the evaluation.

Stufflebeam (2003) thinks that it is important to study no longer only the outcomes of a training path but especially the context, the processes and the changes stimulated during the activities, based on a mature reflection on decision-making. An important formative function of the evaluation is emphasized, because the evaluation has the task of giving the decision-makers information, useful not only for a final purpose but also for improving and 
orienting the whole of the educational activities. In this model, you can find a high degree of flexibility and dynamism. The focus is placed on the global design of the evaluation system, whilst there is less interest in fixing indicators

and procedures. An eclectic use of the methods is made, more than sticking to the procedural criteria and rigid grids, because the key activity is the interpretation of the object being evaluated. It is observed and monitored in its evolution in order to mature decisions. Indeed, the objective of the evaluation is that of decision-making (Stufflebeam, 2003). It is the "philosophy" of a phenomenological and hermeneutic approach to the evaluation of the quality of educational work, whose aims are the improvement and orientation of the path and the analysis of the subject being evaluated in its context, in the middle of the process of change, in order to take decisions. Applied to evaluation, it allows grasping hidden and less formalized dimensions of the educational work. The fundamental characteristics of the proposal are expressed as follows: "not to prove but to improve" (Stufflebeam, Shinkfield, 1985). Evaluation must not test but above all improve the processes and focus on the hermeneutic dimension of the evaluators. A responsive evaluation is considered that one which is developed answering to the needs and questions raised by the stakeholders (Perla, 2004; Patton, 1990), by the context, by the players involved, according to a bottom-up logic (cf. CIRCE site, University of Illinois; http://education.illinois.edu/circe/). This is an idiographic model, focused on the individual concrete activities and on the opinions and personal interpretations of the situation considered from those operating in it, which accepts the diversity of the perspectives. Responsive evaluation - also called sensitive evaluation - is based "on what people do naturally to evaluate things, i.e. observe and react, and it uses a type of spontaneous communication of the outcomes of the evaluation and aims at the usefulness of the results for the people who take part in the programme evaluated" (Pandolfi, 2000, p. 52). Stake (1988), stressing the concept of a phenomenological, hermeneutic and reflective evaluation, states that the value of the activity or of a performance cannot be expressed by a score of a test, but by the best "description" and "interpretation" directly by the participants. He suggests abandoning precise measuring, in favour of the meanings attributed to the evaluating actions by the people involved. The task of the evaluation concerns acquiring information, that is really useful for understanding the complexity of the educational situation. The meanings emerge through the analysis of the points of view and opinions of the participants.

Stake's responsive evaluation criticizes the rational patterns, typical of the previous modelizations, because they reduce the process of evaluation in the educational context to mere measuring techniques, assigning to it purposes of an exclusively pragmatic nature. He focused on the singularity of the evaluating action and on the holistic, systemic and hermeneutic dimension of each process of evaluation (Perla, 2004). For Stake, the protagonists of the evaluation - the evaluator and the person being evaluated, the educator and the person being 
educated - are included in the same system of relations. Both of them are observers and both take part in the same process. Evaluation can be used to make them grow together and in the direction of permanent reflectivity and selfreflectivity. The theory of complexity emphasizes the need to represent all the points of view in the judgement. Evaluation should gather the diversity of perspectives, promoting the qualitative growth of all, although in reciprocally distant positions. This is, for Stake (1988), a formative and qualitative way to innovation through evaluation. The main references of the process of evaluation are the judgements and interpretations of the people. Each stakeholder makes his contribution to the evaluating action, that develops according to the argumentative and critical competence that each person implements. The evaluator is the coordinator of this evaluation dynamic, not looking for generalization. The hermeneutic approach considers what has value for the different stakeholders, stimulates deep awareness, gathers knowledge as a product of listening to everyone's experiences, expectations, fears and anxieties (Perla, 2004). The evaluator reveals the meanings which each person attributes to the reality assessed (Widdershoven, 2001; Guba, Lincoln, 1989). According to Stake (1988), any educational project should be based on the issues of those directly concerned, involving all - designers, participants, evaluators - in the same action. The responsive evaluation gives great importance to the person, reflexivity and thinking, trusting in the sense of responsibility of those involved in the evaluation, in their critical skills, their authentic interest in changing for the better (Guasti, 1996). Evaluating becomes, then, the equivalent of thinking (Dewey, 1939). The evaluator has the task to facilitate this activity, especially in those involved in projects of education and training.

\section{Supervision and Evaluation}

Supervision can be used in all the multiple educational contexts, as it is a transversal practice. Supervision is an important context of training, which brings together a group of professional educators coordinated by a supervisor, who helps them reflect. Evaluation is the "nucleus of clinical supervision" (Bernard \& Goodyear, 1998, p. 152). Some of the practitioners - who exchanged practices between different nationalities during the EduEval Project workshop in Crete and, then, used the wiki system to continue online the discussion on the various approaches and methods of evaluation - presented their use of supervision as a form of evaluation. They understood supervision as a privileged place of thinking, as opposed to the emergency and haste of doing, in which it becomes possible to rethink the professional action, deconstructing its meanings and the frames of reference. Supervision structures a context where theory and practice, emotions and cognitions, values, representations and fears, anxieties and conflicts can be made to dialogue in continuation. The supervisor continuously offers feedback and interpretations to the educators, on their 
considerations and subjects. In this way, the supervisor continuously evaluates the resistance of the theoretical structure (Oggionni, 2013, p. 74; Bisio, 2002) and its connections with practical behaviour, performing the function of reorientation of the educational action. Supervision is aimed at developing reflective competences, capable of investigating the fundamentals of one's professionalism. Reflective thought on experience (Schon, 1987; Dewey, 1938) has a strong heuristic, investigative and transformative value of the educational practices, being identified as an important resource both on the practical and on the theoretical side. Supervision has the task of increasing the production of knowledge and developing the competences of the educators: therefore it is a tool of professional growth. Supervision can therefore be a tool for the evaluation of strengths and criticalities of the educational work. Supervision must bring about changes in the depth of the understanding of events, in recovering overlooked variables, in better mastering the different types of languages, in managing relational dynamics and in establishing a new climate and method of work (Barone, Bruschetta, Giunta, 2010).

Both the processes and the path of the participants can be evaluated. In turn, supervision can be evaluated by educators and clients, with respect to its capacity of having generated learning about the self, the team and group dynamics as well as with respect to the analysis of the educational contexts and processes. Different methods of evaluation can be used with different levels of depth and involvement. "The process of evaluation can be carried out at an ad hoc meeting of the team or of supervision, in the presence/absence of the coordinator and/or supervisor; in a dimension of dialogue or adopting the more technical method of certification" (Oggionni, p. 79). In this case, forms to be filled in at the end of the supervision sessions are used, indicating opinions mostly quantitative considering the type of methodologies adopted -, learning and outcomes of the supervision. The organizations also implement quality through the establishment of regular paths of supervision, which then raise the question of evaluating the efficacy of the processes of supervision. In this case, the organizations check supervision through evaluation. However, this is certainly a risk because the educators could feel that they are not safe or not in a protected place, where they can express themselves calmly and freely, without any dimensions of judgement which block the development of thought. The practice of supervision is part of a path of lifelong education (Regoliosi, Scaratti, 2002; Raineri, 2003; Lichtner, 2003), going through stages of experimentation, evaluation and redesigning, facing constant monitoring of the needs and learning of the individual or of the team. Above all, supervision must be included in a continuous process of professional learning and rethinking of one's own experience and placed in the concrete organization of work. It must be understood as one of the fundamental tools to offer and to ask for in order to carry out one's work well in help relations. 


\section{A case-study}

It is here described how supervision, though is not primarily dedicated to evaluation at a formal level, however can become a kind of evaluation, at a not formal level. In this context, we refer to the hermeneutic and clinical approach to evaluation (Widdershoven, 2001; Bernard \& Goodyear, 1998). One of the central problems the supervisor has to deal with is the question of the so-called resistances or defences of the educators taking part in the supervision, that the supervisor has the task of bringing out, naming and re-elaborating (Oggionni, 2013, p. 82). During the discussion in the Crete workshop, one Italian practitioner reported the case of a path of supervision with a group of about 13 educators, mainly male, with the presence of only three women. The age varied from 30 to 45. The context was that one of a big Provider of socio-educational services for disabled people, located in a medium size town in the north of Italy. The supervision here described follows a psycho-pedagogical and narrative approach, looking for the meanings and the emotions that are always conditioning the educational processes (Oggionni, 2013; Regoliosi, Scaratti, 2002). The practitioner had followed in supervision for about a year and a half this team of a day socio-educational centre for disabled adults. From the very beginning, the female supervisor had found very high levels of defence in the educators, in particular the male group. The supervisor began the session asking how they were and how the week had been. The recurring answer was that everything was fine and that there were no problems or conflicts, the work was tiring but everything was going well. Of course, they stated, they did not clearly understand the need for supervision and they were proud of having made a previous supervisor leave. After a phase in which the supervisor tried to negotiate with the educators the direction that they wanted to give to the supervision, so that the objectives declared by the supervisor and by the client to work on the group dynamics, on the conflicts, on the anxieties caused by the work, by contact with difficult users etc. - did not seem to have been imposed from above, the supervisor dealt, for a certain period of time, with their discontent and complaints about the bosses, placed at various hierarchical levels. For a long time, all the blame for the malaise of the group was shifted on the authoritarian, imposing, insensitive and inattentive behaviour of the management. The group unleashed all their anger on those in positions of authority, but without assuming the power of membership more than to a certain extent. The supervisor continuously referred to them the infantile need to always blame the parents, without ever allowing herself take that part of power which, nevertheless, is due to those who enter into professional relations: for example, the power to ask for explanations, to be informed, to challenge what they were ordered to do. They naturally complained a great deal about the commitment and the effort that continuously being in contact with the disabled required, where there were not many possibilities of reaching consistent progress, where 
the daily encounter with frustration for the efforts made, without seeing significant results, was a constant.

In particular, the element that tired them most and caused the aggressiveness of the educators, was in the sense of unexpected inclusions of new users and in changes of environment, as in the case of a move. The supervisor, continuously observing, monitoring, weighing up and evaluating the words and behaviour of the educators, referred several times that the group seemed not to have negative capacities, i.e. that capacity of being able to stay in uncertainty that generates insecurity (Bion, 1970). Therefore, every order that was not prepared at length, was perceived by the educators as something that was not tolerable, something that abruptly broke their fragile equilibrium. The point is that however- the supervisor evaluated- the educators were fragile also because - in a vicious circle - they never accepted subjecting themselves to thinking about the great malaise that was hidden behind their artificial equilibrium. In order not to be in emotive contact with the efforts and the malaise caused by their concrete professional activity, they always refused to proceed with reflective work, continuously annulling the potential wealth of a freer way of expressing themselves. Finally, after a long period of time, the group began to abandon the focus on complaining about their bosses. The discourse in supervision began, although with great effort and digressive actions, to concern the opinions and the behaviour of the educators themselves. At times, the compactness of the group cracked, either because of some rare divergent feminine voice or because one of the males allied with the supervisor, pointing out to his other colleagues the fact that they were laughing, making jokes, talked about other things all the time, or for some unexpected event, such as, for example, the entrance of a new educator in the group. At those rare moments of breaking down the usual barriers to the possibility of thinking (Bion, 1970), the supervisor proposed reflective questions, to try and lead the group to becoming aware of the opportunity for the group to grow, at the time when the compact wall was breaking down.

At a certain point, a new female educator arrived, who stayed slightly on the sidelines of the group of male educators. The supervisor invited her to speak, asking her how she had felt being included in a group that was already formed, and then went on to ask the rest of the group of educators what type of group they thought they were, if they thought they were a welcoming, open group, capable of opening up to a newcomer. This question by the supervisor caused a certain bewilderment amongst the educators, who were not expecting it and were floored by being forced to observe themselves, interrogating themselves on the group itself. However, the walls soon closed up again, as if the question they had been asked had hit the mark, i.e. the hidden point of the nature of the group: a basic hostility that they tried never to have discovered. The supervisor then had personal problems in the following months and, for some time, she could not return to the team. From a certain point onwards, however, she realized that 
she did not want to go back and continue as before. She submitted to in-depth evaluation both the behaviour of the educators and the very process of supervision and decided that, for a little while, she should not return, to allow all the time necessary to bring out the need and also, the desire, for supervision. The supervisor evaluated at length the hostility of the group: in the face of such a thick wall of fear and resistance to think and perceive the emotions in the field, the only path was to be absent, making the group feel what they were missing. She also evaluated that she would not have continued the supervision, as the price to pay to make the educators return to perceiving their needs was that of interrupting a serious, deep and sensitive commitment but taken for granted by the group of educators, especially by its male members. In fact, she returned after several months only once, leading the group to express their anger and their regret - at last - for the loss of the supervision. In this way, the supervisor opened up the path for a new supervision, but with another leader.

\section{Conclusions}

When we raise the problem of evaluating educational processes and events, we find ourselves in the face of a great complexity and an intricate series of theoretical-methodological-practical questions to disentangle. In particular, evaluation understood as certification of competences, of adaptation to procedures, of confirmation of alignment with certain synthetic indicators, although very important for the paradigmatic value contained in it, nevertheless does not fully seize on the variety of problems, conscious and subconscious, visible and hidden, that are an essential part of educational actions. Hermeneutic evaluation poses the problem of finding the meanings of the points of view of the participants and, with the help of disciplinary knowledge which has studied emotions - such as psychoanalysis -, also which are the affective and group dynamics. This is where the meeting point with the activity of supervision, which consists precisely of a practice guided by a leader who helps the educators better understand their theoretical frames of reference, their basic educational models, their involvements and emotional projections on the users and colleagues, lies. If reference is made to the general concept of reflective practice, thoughts go to Dewey, who theorized the heuristic, investigative and transformative capacity of reflective thought. Reflection becomes the means through which to bring out the quality that intrinsically connotes experience. $\mathrm{He}$ maintains that "the world in which we immediately live, that in which we strive, succeed, and are defeated is pre-eminently a qualitative world". From this, it can be deducted that "the immediate existence of quality, and of dominant and pervasive quality, is the background, the point of departure, and the regulative principle of all thinking". Reflective thinking, therefore, allows upturning the usual logic that saw recourse to an expert knowledge, from the outside, to privilege knowledge from the grassroots. It is knowledge faithful to the 


\section{SOCIETY. INTEGRATION. EDUCATION. Volume IV}

situations, which, by their nature, are presented as unique and cannot be traced back to standard generalizations. Supervision and Evaluation are two important tools for developing the professionalism of operators and, in certain cases and according to certain types of approaches, can flow into a single great educational power.

\section{References}

Aichorn, A. (1978). Gioventù disadattata: la psicoanalisi nell'educazione curata dagli enti assistenziali. Roma: Città Nuova.

Balint, M. (1964). The Doctor, his Patient and the Illness, London: Pitman.

Barone, R., Bruschetta, S., Giunta, S. (2010). Gruppoanalisi e comunità terapeutica. Uno strumento di lavoro basato su supervisione, valutazione e ricerca. Milano: Angeli.

Belardi, N., Wallnofer, G. (2007). La supervisione nelle professioni educative. Trento: Erickson.

Bernard, J.M., Goodyear, R.G. (1998). Fundamentals of Clinical Supervision. Needham Heights, MA: Allyn \& Bacon.

Bernfeld, S. (1971). Sisifo, ovvero i limiti dell'educazione. Firenze: Guaraldi.

Bion, W.R. (1970). Attention and interpretation. London: Tavistock Publications.

Bisio, C. (a cura di) (2002). Valutare in formazione. Azioni, significati e valori, Milano: Angeli.

Bruzzone, D. (2010). L'operatore sociale come professionista riflessivo. Milano: Angeli.

Burton, J., Launer, J. (eds.) (2003). Supervision and Support in Primary Care. Oxford: Radcliffe Medical Press.

Castellucci, A., Saiani, L., Sarchielli, G., Marletta, L. (Eds.) (2007). Viaggi guidati. Il tirocinio e il processo tutoriale nelle professioni sociali e sanitarie. Milano: Angeli.

Cellentani, O. (2004). Manuale di metodologia per il servizio sociale. Milano: Angeli.

Dewey, J. (1938). Experience \& Education. New York: Kappa Delta Pi.

Dewey, J. (1984). The Later Works of John Dewey . Carbondale: Southern Illinois University Press

Dewey, J. (1939). Theory of Valuation. Chicago: Chicago University Press.

Dozza, L., Setting e dinamiche anti-gruppo nei gruppi di formazione. In Contini, M. (a cura di) (2000). Il gruppo educativo: luogo di scontri e di apprendimento. Roma: Carocci.

Frabboni, F., Wallnofer, G., Belardi, N., Wiater, W. (Eds.). (2007). Le parole della pedagogia. Torino: Bollati Boringhieri.

Guasti L. (1996). Valutazione e innovazione. Novara: De Agostini.

Guba, E. G., Lincoln, Y. S. (1989). Fourth Generation Evaluation. Newbury Park, CA: Sage.

Hadji, C. (1995). La valutazione delle azioni educative. Brescia: La Scuola.

Horder, J. (2001). The First Balint Group. Brit. J. Gen. Practice 51, 1038-9.

Lichtner, M. (2008). Esperienze vissute e costruzione del sapere. Le storie di vita nella ricerca sociale. Milano: Angeli..

Lichtner, M. (2002). La qualità delle azioni formative. Criteri di valutazione tra esigenze di funzionalità e costruzione del significato. Milano: Angeli.

Merlini, F., Filippini, S. (2006). La supervisione al servizio della valutazione. In Prospettive sociali e sanitarie, 19, 2006, pp. 7-11.

Oggionni, F. (2013). La supervisione pedagogica. Milano: Angeli.

Otten, H. (1998). Balint work in Germany. In Journal of the Balint Society. 26, 16-19.

Palmieri, C., Pozzoli, B., Rossetti, S.A., Tognetti, S. (2009). Pensare e fare tirocinio. Manuale di Tirocinio per l'educatore professionale. Milano: Angeli.

Palumbo, M. (2001). Il processo di valutazione. Milano: FrancoAngeli. 
Pandolfi L. (2012). Valutare servizi educativi. Un'introduzione. Lecce: Pensa.

Patton, M.Q. (1990). Qualitative Evaluation and Research Methods. Newbury Park, CA: Sage Publications.

Perla, L. (2004). Valutazione e qualità in università. Roma: Carocci.

Pinder, R., McKee, A., Sackin, P., Salinsky, J., Samuel, O., Suckling, H. (2006). Talking about my patient: the Balint approach in GP education. Occasional Paper No. 87, London: RoyalCollege of General Practitioners.

Ranieri, M.L. (2003). Il tirocinio di servizio sociale. Milano: Angeli.

Regoliosi, L., Scaratti, G. (a cura di). (2002). Il consulente del lavoro socio educativo. Roma: Carocci.

Richmond, M. (1917). Social diagnosis. New York: Russel Sage Foundation.

Salinsky, J., Sackin, P., Southgate, L. (Eds.) (2000). Foreword to What are You feeling Doctor: identifying and avoiding defensive patterns in the consultation. Oxford: Radcliffe Medical Press.

Schön, D. (1993). Il professionista riflessivo. Bari: Dedalo.

Scriven, M. (1991). Evaluation Thesaurus. Newbury Park, CA: Sage Publications.

Stake, R.E. (1988). La valutazione "responsiva". In Giovannini, M.L. (Ed.) (1988). La valutazione delle innovazioni nella scuola. Bologna: Cappelli.

Stufflebeam, D. (2003). The CIPP model for evaluation. In Stufflebeam, D., Kellaghan, T. (Eds.), The international handbook of educational evaluation. Boston: Kluwer Academic Publishers.

Stufflebeam, D., Shinkfield A.J. (1985). Systematic Evaluation, Boston: Kluwer Nijhoff.

Widdershoven, G. (2001). Dialogue in Evaluation: A Hermeneutic Perspective. In Id. (2001). Evaluation. London: Sage, 7, (2): 253-263.

Widdershoven, G., Sohl, C. (1999). Interpretation, Action, and Communication: Four Stories about a Supported Employment Program', in Abma, T.A. (Ed.) (1999). Telling Tales, on Narrative and Evaluation, Advances in Program Evaluation. 6, pp. 109-30. Stamford, CT: JAI Press.

Zannini, L. (2005). La tutorship nella formazione degli adulti. Uno sguardo pedagogico. Milano: Guerini. 